\title{
Development of simple HPLC/UV with a column-switching method for the determination of nicotine and cotinine in hair samples
}

\author{
Masayoshi Tsuji ${ }^{1 *}$, Yayoi Mori ${ }^{1}$, Hideyuki Kanda ${ }^{2}$, Teruna Ito $^{1}$, Tomoo Hidaka ${ }^{1}$, \\ Takeyasu Kakamu ${ }^{1}$, Tomohiro Kumagai ${ }^{1}$, Takehito Hayakawa ${ }^{1}$, Yoneatsu Osaki ${ }^{3}$, \\ Tetsuhito Fukushima ${ }^{1}$ \\ ${ }^{1}$ Department of Hygiene and Preventive Medicine, School of Medicine, Fukushima Medical University, Fukushima, Japan;
*Corresponding Author: tsuji@fmu.ac.jp
${ }^{2}$ Department of Epidemiology and Public Health, School of Medicine, Yokohama City University, Yokohama, Japan
${ }^{3}$ Division of Environmental and Preventive Medicine, Department of Social Medicine, Faculty of Medicine, Tottori University, Yo-
nago, Japan
}

Received 26 February 2013; revised 28 March 2013; accepted 8 April 2013

Copyright (C) 2013 Masayoshi Tsuji et al. This is an open access article distributed under the Creative Commons Attribution License, which permits unrestricted use, distribution, and reproduction in any medium, provided the original work is properly cited.

\section{ABSTRACT}

Nicotine and cotinine in hair are good biomarkers for assessing long-term exposure to smoking. However, analytical devices such as GC/MS are associated with high cost and are not widely used. HPLC/UV is used widely in laboratories, but is unsuitable for measurement of minor constituents, except when using the column-switching method. Thus, we aimed to establish a simple, inexpensive and sensitive method based on HPLC/UV with column switching for measuring nicotine and cotinine in hair. First, we compared the presence and absence of a column selection unit. We then measured amounts of nicotine and cotinine in hair samples collected from the general population, and compared both the corresponding levels and the detection limits with those in previous studies. Finally, initial and running costs of HPLC/UV were compared with other analytical methods. As one of the results, the areas of nicotine and cotinine measured by HPLC/UV with column-switching method were 12.9 and 16.9 times greater, respectively, than those without the column-switching method. The amount of nicotine and cotinine in hair was significantly correlated to number of cigarettes smoked per day $(r=0.228, p=0.040)$. In addition, the HPLC/UV method showed similar sensitivity and detection limit (nicotine, $0.10 \mathrm{ng} / \mathrm{mg}$; cotinine, $0.08 \mathrm{ng} / \mathrm{mg}$ ) as reported in previous studies. The cost of the HPLC/UV method is lower than that of other analytical methods. We were able to establish a low-cost method with good sensitivity for measuring nicotine and cotinine in hair. The HPLC/UV with a column-switching method will be useful as a first step in screening surveys in order to better understand the effects of smoking exposure.

Keywords: HPLC/UV; Column-Switching Method; Nicotine; Hair; Cotinine

\section{INTRODUCTION}

The risks of smoking are widely recognized and taking action against smoking continues to be a priority issue for public health. Death by cancer or ischemic heart disease is reported to be a major risk of smoking [1,2]. Thus, environmental countermeasures need to be taken for both smokers and non-smokers.

Biological monitoring is important as a means to evaluate exposure to smoking. In previous studies, levels nicotine and its metabolite, cotinine, were measured in the urine or saliva of smokers [3-5]. However, the levels of nicotine or cotinine in these samples may reflect acute exposure to smoking, but not the amount of habitual smoking. Because human hair grows about $1 \mathrm{~cm} / \mathrm{month}$, it is useful in biological monitoring in the medium or long term [6,7]. In addition, the amount of nicotine and its metabolites in the hair reportedly decreases slowly; a decrease of less than $10 \%$ was observed after being left to stand for one week at room temperature [6].

In previous studies, measurement of nicotine or co- 
tinine in hair has been performed by gas chromatography with mass spectrophotometry (GC/MS) $[8,9]$, but this method has high initial and running costs. More recently, high-performance liquid chromatography with electrochemical detection (HPLC/ECD) has been used for the determination of nicotine and cotinine because of its high sensitivity. The initial and running costs of HPLC are lower than those of GC. However, ECD detectors are not commonly present in laboratories, while UV detectors are much more common. Unfortunately, UV detectors are unsuitable for measurement of small amounts of compounds in hair due to poor sensitivity. It has been reported that UV detectors can be installed on columnselection units $[10,11]$, but there have been no reports on the measurement of nicotine in hair using this approach. The column-switching method is able to concentrate samples for analyses; thus, the column-switching method may be used as a method for increasing the sensitivity of HPLC/UV.

This study aims to establish a simple, cheap and sensitive method based on HPLC/UV with column-switching in order to measuring nicotine and cotinine in hair. First, we compared the presence and absence of a column selection unit, and we examined the intra- and inter-assay reproducibility of HPLC/UV with column-switching. We then measured the amounts of nicotine and cotinine in hair samples collected from the general population, and compared the quality controls with previous studies. Finally, the initial and running costs of HPLC/UV were compared with other analytical methods.

\section{METHODS}

\subsection{Usefulness of HPLC/UV with Column-Switching Method}

\subsubsection{Sensitivity of HPLC/UV with Column-Switching Method}

This study examined the sensitivity of the columnswitching method in a preliminary experiment using nicotine and cotinine standard solutions (both $1000 \mathrm{ng} / \mathrm{ml}$; Sigma-Aldrich, Tokyo, Japan). Chromatograms of nicotine and cotinine were compared by area. An internal standard of $100 \mathrm{ng} / \mathrm{ml}$ N-ethyl norcotinine (NENC) in methanol was used. Some differences between the preliminary experiment and the present study were found with respect to analytical column, flow rate, injection volume, and introduction of column-switching. Inertsil ODS-3V (GL Sciences, Tokyo, Japan) was used as an analytical column, with a $1.0 \mathrm{ml} / \mathrm{min}$ flow rate and a 50 $\mu \mathrm{l}$ injection volume in the preliminary experiment. The present study also introduced a column selection unit HV-2080-01 (JASCO, Tokyo, Japan), as a columnswitching method, for greater sensitivity than in the preliminary experiment. The analytical column used was the
Ascentis Express C18 Column $(100 \mathrm{~mm} \times 3.0 \mathrm{~mm} \times 2.7$ $\mu \mathrm{m}$; Sigma-Aldrich) with the PU-2089 pump (JASCO). The mobile phase in the analytical column consisted of ammonium formate $(50 \mathrm{mM}, \mathrm{pH} 4.3)$ : acetonitrile $=96: 4$ at a flow rate of $0.4 \mathrm{ml} / \mathrm{min}$. The concentrating column used the Develosil ODS-UG-5 Column $(10 \mathrm{~mm} \times 4.0$ $\mathrm{mm}$ i.d.; Nomura Chemical, Aichi, Japan) and the DPmodel 203 pump (Eicom, Kyoto, Japan). The mobile phase of the concentrated column consisted of ammonium formate $(50 \mathrm{mM}, \mathrm{pH} 9.0)$ with a flow rate of 0.5 $\mathrm{ml} / \mathrm{min}$. The injection volume was $200 \mu \mathrm{l}$. Other conditions were the same for both the preliminary experiment and the present study. We used the HPLC LC-2000 Plus Series, the AS-2055 auto sampler, the UV-2075 detector set at $260 \mathrm{~nm}$, the ChromNAV data disposal device (all from JASCO), and the Waters-CHM column oven (Nihon Waters, Tokyo, Japan) with a column oven temperature at $40^{\circ} \mathrm{C}$.

\subsubsection{Intra- and Inter-Assay Reproducibility of HPLC/UV with Column-Switching Method}

The HPLC/UV with column-switching method was examined for intra-assay and inter-assay reproducibility. With regard to pre-treatment for hair, similarly to previous studies on hair analysis $[12,13]$, hair samples were placed in test tubes and washed three times using $3 \mathrm{ml}$ of dichloromethane. After the hair sample was dried, it was weighed, and the following treatment for about $40 \mathrm{mg}$ of hair was used. Samples were mixed with $1.6 \mathrm{ml}$ of $\mathrm{NaOH}(2.5 \mathrm{M})$ and $60 \mu \mathrm{l}$ of NENC (1000 ng/ml; Cosmo Bio, Tokyo, Japan) as an internal standard, followed by incubation at $40^{\circ} \mathrm{C}$ until the hair was completely dissolved. Next, $4 \mathrm{ml}$ of solvent mixture (chloroform: isopropyl alcohol $=95: 5(\mathrm{v} / \mathrm{v}))$ was added and the mixture was vortexed for $2 \mathrm{~min}$. The mixture was then centrifuged for $5 \mathrm{~min}$ at $2000 \mathrm{rpm}$, and the supernatant was aspirated under a fume hood. Next, $2 \mathrm{ml}$ of $\mathrm{HCl}(0.5 \mathrm{M})$ was added, followed by vortexing for 2 minutes. The mixture was centrifuged for $5 \mathrm{~min}$ at $2000 \mathrm{rpm}$, and the supernatant was transferred to another test tube. $\mathrm{NaOH}$ $(0.4 \mathrm{ml} ; 2.5 \mathrm{M})$ was then added to the test tube. In addition, $1.6 \mathrm{ml}$ of ammonium chloride (pH 9.5) and $4 \mathrm{ml}$ of solvent mixture (chloroform: isopropyl alcohol $=95: 5$ $(\mathrm{v} / \mathrm{v}))$ also was added to the test tube, followed by vortexing for 2 minutes. The mixture was centrifuged for 5 min at $2000 \mathrm{rpm}$, and the supernatant was discarded and dried under a nitrogen stream. The extract was dissolved with $600 \mu \mathrm{l}$ of ammonium formate $(0.5 \mathrm{M})$, centrifuged for $1 \mathrm{~min}$ at $2000 \mathrm{rpm}$, and filtered with a $0.45 \mu \mathrm{m}$ filter. Solvent $(200 \mu \mathrm{l})$ was then injected into the HPLC system and analyzed. This study was performed under the HPLC/UV conditions described previously. For intraassay assessment, measurements were performed every hour for 5 hours, and for inter-assay assessment, mea- 
surement was performed once daily for 5 days.

\subsection{Screening of Nicotine and Cotinine in Hair}

\subsubsection{Subjects and Time Period}

Two thousand subjects were selected in a two-stage stratified random sampling chosen from the "Basic Resident Registries" of municipalities all over Japan. We performed both a questionnaire survey and hair-cutting by home visits. Questionnaires remained anonymous in order to protect private information, and informed consent was obtained from each subject. Questionnaires about smoking behavior were completed during home visit interviews.

\subsubsection{Hair Sample Collection, Preservation and Measurement Method}

Nicotine and cotinine were measured in hair samples collected from 294 people in 2009 and 2010. Subjects were 294 people assessed for smoking status by questionnaire. Two hundred and eighty-seven samples were used for analysis due to a lack of complete data in 7 samples. We developed a hair-cutting kit and explanatory leaflet for the hair extraction method, with the aim of safely colleting hair samples with affecting subject esthetics (Figure 1). The kit included a plastic bag and a rectangular sheet of construction paper $(15 \mathrm{~cm} \times 5 \mathrm{~cm})$, with a red line at the $1 \mathrm{~cm}$ from the bottom and pressure-sensitive adhesive double-coated tape above the red line. To obtain a hair sample, the top edge of the paper was first applied to the skin of the head, tape-side down. Hair was then affixed to the tape, and then, with hair- cutting scissors, the hair sample was cut at the red line on the paper. Hair used for measurement was that from the cut point to a length of $5 \mathrm{~cm}$. Each hair sample and attached paper was then placed in a plastic bag and stored at $-80^{\circ} \mathrm{C}$ in a freezer. This study was performed under the pre-treatment and HPLC/UV method conditions described previously.

\subsubsection{Screening Survey}

Smoking information was assessed from questionnaires associated with 287 samples. Participants were categorized into 2 groups; non-smokers and smokers. The mean values of nicotine and cotinine in the hair in each group was calculated. To examine the usefulness of the HPLC/UV method, present methods and results were compared with major studies. In addition, the correlation of sum total nicotine and cotinine in hair and number of cigarettes smoked per day were checked for the smoker group. This statistical analysis was conducted using SPSS statistics 17.0 (Nihon IBM, Tokyo, Japan). All probability values were two-tailed and all confidence intervals were estimated at the $95 \%$ levels.

\subsection{Comparison of Apparatus Costs}

Initial and running costs were compared for each analytical apparatus and we evaluated the usefulness of HPLC/UV. For market rate costs, we referred to a report by Benowitz [14] and analytical apparatus catalogs. We categorized initial costs under US\$50,000 as "Low", US\$50,000 - \$100,000 as "Moderate", US\$100,000 $\$ 200,000$ as "High", and over US\$200,000 as "Extremely high", with US\$1 = 100 yen. Meanwhile, run-

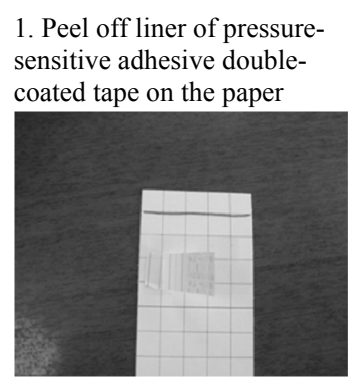

4. Press tape-side firmly onto the hair

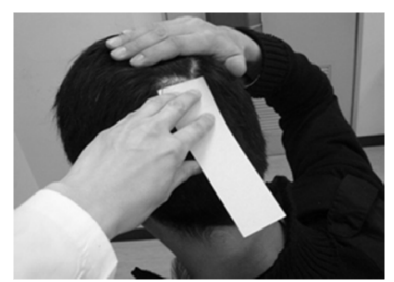

Note: Repeat procedure a second time.
2. Hold down section of hair by hand

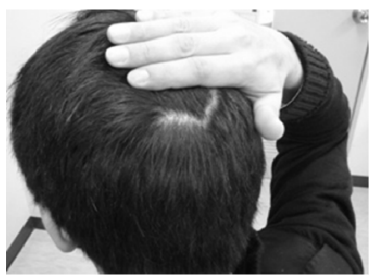

5. Hold up the paper and with haircutting scissors, and cut along the red line

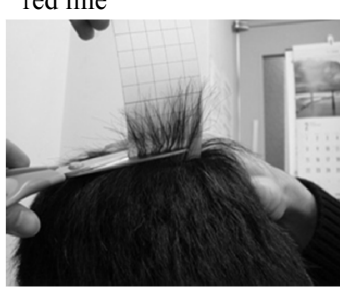

3. Apply the edge of the paper tape-side down to the scalp

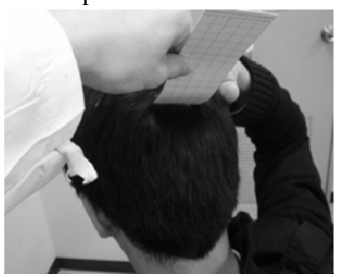

6. Place the hair sample and attached paper into the plastic bag

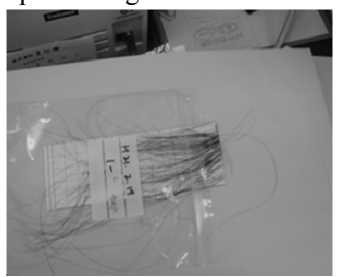

Figure 1. Hair sampling method. 
ning costs were divided into 3 categories; "Low" (under US\$3000/year), "Moderate" (US\$3000 - \$5000/year), and "High" (over US\$5000/year), with US\$1 = 100 yen.

\section{RESULTS}

\subsection{Usefulness and Accuracy of HPLC/UV with Column-Switching Method}

For measurement of nicotine and cotinine in hair samples, we used the HPLC/UV with column-switching method. The HPLC/UV with column-switching method was shown have better sensitivity when compared with preliminary experiments (Figure 2). Nicotine and cotinine levels measured by the column-switching method were 12.9 times and 16.9 times greater, respectively, then that of the preliminary experiment. The area of the NENC peak measured by the column-switching method was shown to be 12.2 times that of the preliminary experiment. In addition, measurement time was shortened to around $8 \mathrm{~min}$ by the HPLC/UV without column-

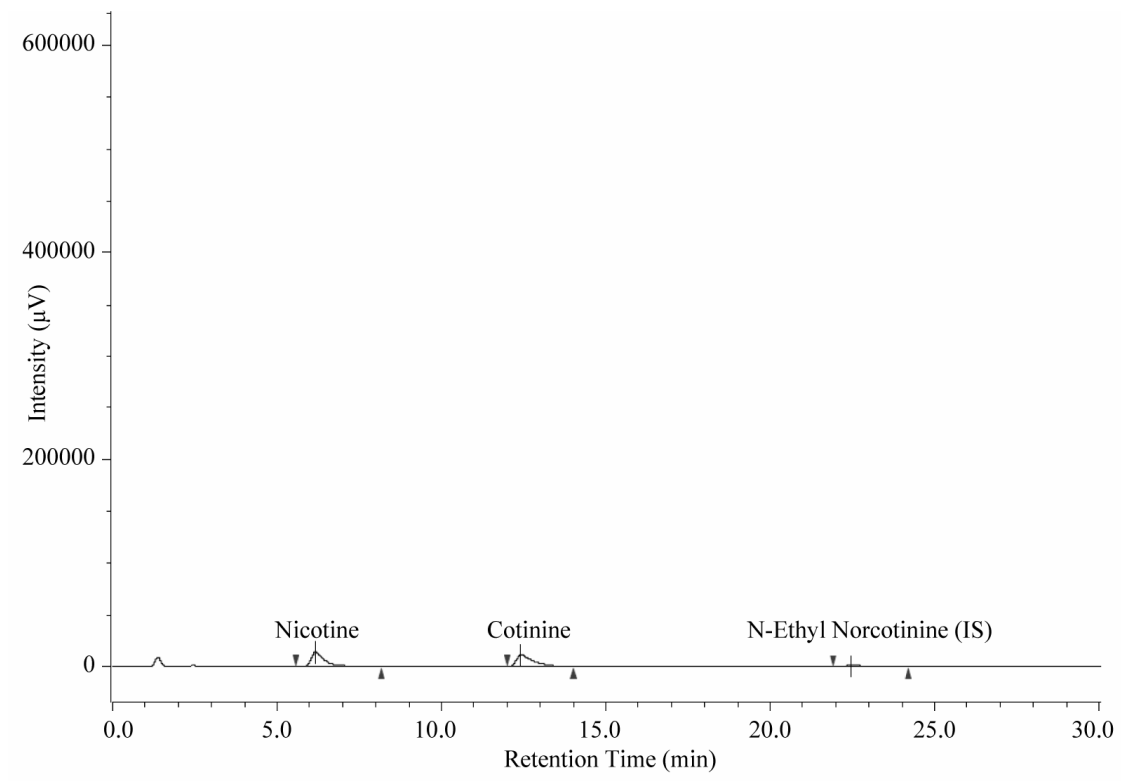

(a)

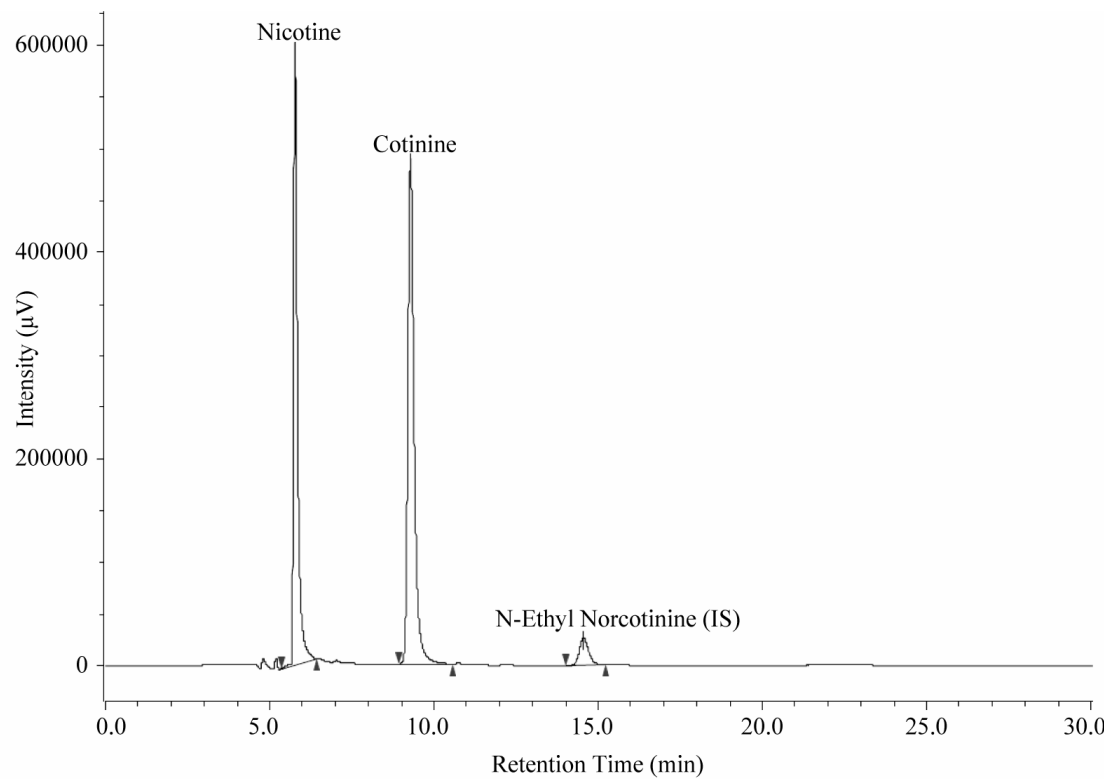

(b)

Figure 2. Chromatograms of standard nicotine and cotinine solutions. (a) Results of preliminary experimet; (b) Results using column-switching method. Note: (b) shows results from the measurement method in the preliminary experiment added to those from the column-switching method; IS: internal standard. 
switching method.

Intra- and inter-assay reproducibility was stable (Table 1). Results for intra-assay assessment were $92.2 \pm 2.7$ $\mathrm{ng} / \mathrm{mg}$ for nicotine and $10.3 \pm 0.2 \mathrm{ng} / \mathrm{mg}$ for cotinine (Table 1(a)). Results for inter-assay assessment were $87.0 \pm 2.8 \mathrm{ng} / \mathrm{mg}$ for nicotine and $10.4 \pm 0.3 \mathrm{ng} / \mathrm{mg}$ for cotinine (Table 1(b)).

\subsection{Screening Nicotine and Cotinine in Hair by HPLC/UV with Column-Switching Method}

Among 287 hair sample providers, 205 were nonsmokers and 82 were smokers. The sum total nicotine and cotinine in hair and the number of cigarettes smoked per day were significantly correlated in smokers (Figure $3 ; \mathrm{r}=0.228, \mathrm{p}=0.040$ ).

The HPLC/UV method used in our study showed a similar sensitivity and detection limit as previous studies for both nicotine and cotinine (Table 2). In our 2 groups, the mean level of nicotine and cotinine in hair samples was $1.60 \mathrm{ng} / \mathrm{mg}$ and $0.20 \mathrm{ng} / \mathrm{mg}$ among non-smokers, $23.30 \mathrm{ng} / \mathrm{mg}$ and $1.70 \mathrm{ng} / \mathrm{mg}$ among smokers, respectively. Non-smokers in previous studies showed a range of $0.58-2.50 \mathrm{ng} / \mathrm{mg}$ nicotine and ND-0.30 ng/mg cotinine in hair samples. Meanwhile, smokers in previous studies showed a range of $6.17-42.40 \mathrm{ng} / \mathrm{mg}$ nicotine and $0.33-6.30 \mathrm{ng} / \mathrm{mg}$ cotinine in hair samples.

Using an $\mathrm{S}$ (signal)/ $\mathrm{N}$ (noise) ratio of $3: 1$, the detection limit for nicotine was about $0.10 \mathrm{ng} / \mathrm{mg}$ and that for cotinine was about $0.08 \mathrm{ng} / \mathrm{mg}$ in hair samples using our method. The ranges for nicotine data obtained by other analytical methods were $0.05-0.50 \mathrm{ng} / \mathrm{mg}$. Our results were within these ranges.

\subsection{Cost Comparison by Analytical Method}

The HPLC/UV method has a relatively low cost when compared to other analytical methods (Table 3). The HPLC/UV method was categorized as "Low" for both initial and running costs. The initial and running costs for
HPLC/UV used in the present study were about US $\$ 25,000$ and about US\$2500/year, respectively. The GC/ MS method, used as a major analytical method, has both "High" initial and running costs.

\section{DISCUSSION}

In the present study, we established a new method using HPLC/UV with column-switching method that has lower costs with similar sensitivity as other analytical methods in order to determine nicotine and cotinine levels in hair samples. Our results suggest that our method allows high sensitivity with good reproducibility to study the effects of long-term exposure to smoking.

This study examined HPLC/UV with column-switching method for higher sensitivity measurement of nicotine and cotinine in hair. In the column-switching method, a large amount of sample solution is added to the concentration column, and trace components are first trapped. The flow path is then reversed, followed by processing with an appropriate amount of liquid solvent and measurement using an analytical column.

Therefore, we were able to concentrate the samples and reduce analysis time. Using the column-switching method, it was possible to measure larger amounts and to increase nicotine and cotinine sensitivity detection by 10 fold vs. that in the preliminary experiment. In addition, we investigated the utility of the column-switching method based on intra- and inter-assay reproducibility. It was not difficult to obtain $200 \mu$ of extraction liquid from samples, and we confirmed effective extraction with high sensitivity. This study showed higher sensitivity than previous reports measuring nicotine and cotinine in hair samples, where HPLC/UV was used and showed a detection sensitivity of $0.20 \mathrm{ng} / \mathrm{mg}$ hair for nicotine and about $0.10 \mathrm{ng} / \mathrm{mg}$ hair for cotinine [26]. Thus, the results demonstrate the utility of the column-switching method.

There was a significant correlation between the number of cigarettes smoked per day and the total amount of nicotine and cotinine in hair samples. In order to avoid

Table 1. Intra- and inter-assay reproducibility of hplc/uv with column-switching method. (a) Intra-assay; (b) Inter-assay.

(a)

\begin{tabular}{lcccccc}
\hline & $1 \mathrm{~h}$ & $2 \mathrm{~h}$ & $3 \mathrm{~h}$ & $4 \mathrm{~h}$ & $5 \mathrm{~h}$ & Mean $\pm \mathrm{SD}$ \\
\hline Nicotine $(\mathrm{ng} / \mathrm{mg})$ & 92.0 & 92.9 & 96.5 & 97.6 & 92.0 & $92.2 \pm 2.7$ \\
Cotinine $(\mathrm{ng} / \mathrm{mg})$ & 10.0 & 10.4 & 10.4 & 10.5 & 10.1 & $10.3 \pm 0.2$ \\
\hline
\end{tabular}

(b)

\begin{tabular}{lcccccc}
\hline & 1 day & 2 days & 3 days & 4 days & 5 days & Mean \pm SD \\
\hline Nicotine $(\mathrm{ng} / \mathrm{mg})$ & 90.6 & 89.1 & 85.7 & 85.9 & 83.6 & $87.0 \pm 2.8$ \\
Cotinine $(\mathrm{ng} / \mathrm{mg})$ & 10.5 & 10.8 & 10.5 & 10.2 & 9.9 & $10.4 \pm 0.3$ \\
\hline
\end{tabular}

Notes: h, hour(s); SD, standard deviation. 
Table 2. Summary of present study and previous studies.

\begin{tabular}{|c|c|c|c|c|c|c|c|c|c|}
\hline \multirow[t]{3}{*}{ Study } & \multirow[t]{3}{*}{ Year } & \multirow[t]{3}{*}{ Country } & \multirow[t]{3}{*}{$\begin{array}{l}\text { Analytical } \\
\text { method }\end{array}$} & \multirow{2}{*}{\multicolumn{2}{|c|}{$\begin{array}{c}\text { Corresponding levels } \\
\text { (ng/mg hair) }\end{array}$}} & \multirow{2}{*}{\multicolumn{2}{|c|}{$\begin{array}{c}\begin{array}{c}\text { Corresponding levels } \\
\text { (ng/mg hair) }\end{array} \\
\text { cotinine } \\
\end{array}$}} & \multicolumn{2}{|c|}{$\begin{array}{l}\text { Limit of detection } \\
\text { (ng/mg hair) }\end{array}$} \\
\hline & & & & & & & & \multirow{2}{*}{ nicotine } & \multirow{2}{*}{ cotinine } \\
\hline & & & & non-smokers & smokers & non-smokers & smokers & & \\
\hline Present study & 2010 & Japan & HPLC/UV & $\begin{array}{c}1.60^{*} \\
(\mathrm{n}=205)\end{array}$ & $\begin{array}{l}23.30^{*} \\
(\mathrm{n}=89)\end{array}$ & $0.20^{*}$ & $1.70^{*}$ & 0.10 & 0.08 \\
\hline Zahlsen et al. [15] & 1994 & Norway & GC/MS & $\begin{array}{c}0.87^{*} \\
(\mathrm{n}=7)\end{array}$ & $\begin{array}{c}42.40^{*} \\
(\mathrm{n}=13)\end{array}$ & & & 0.05 & \\
\hline Eliopoulus et al. [16] & 1994 & Canada & RIA & $\begin{array}{c}1.20^{*} \\
(\mathrm{n}=35)\end{array}$ & $\begin{array}{l}19.20^{*} \\
(\mathrm{n}=36)\end{array}$ & $0.30^{*}$ & $6.30^{*}$ & 0.25 & 0.10 \\
\hline Eliopoulus et al. [17] & 1996 & Canada & RIA & & $\begin{array}{l}19.91^{*} \\
(\mathrm{n}=36)\end{array}$ & & $1.72^{*}$ & 0.50 & 0.25 \\
\hline Nafstad et al. [18] & 1997 & Norway & GC/MS & $\begin{array}{c}2.00^{* *} \\
(\mathrm{n}=24)\end{array}$ & $\begin{array}{l}19.60^{* *} \\
(\mathrm{n}=69)\end{array}$ & & & 0.05 & \\
\hline Al-Delaimy et al. [19] & 2002 & $\begin{array}{c}\text { New } \\
\text { Zealand }\end{array}$ & HPLC/ECD & $\begin{array}{c}0.58^{*} \\
(\mathrm{n}=101)\end{array}$ & $\begin{array}{c}5.62^{*} \\
(\mathrm{n}=127)\end{array}$ & & & 0.10 & \\
\hline $\begin{array}{l}\text { Chetiyanukornkul } \\
\text { et al. }[20]\end{array}$ & 2004 & Japan & LC/MS & $\begin{array}{l}2.50^{*} \\
(\mathrm{n}=9)\end{array}$ & $\begin{array}{c}39.00^{*} \\
(\mathrm{n}=10)\end{array}$ & $\mathrm{ND}^{*}$ & $1.90^{*}$ & 0.08 & 0.01 \\
\hline Klein et al. [7] & 2004 & Canada & RIA & & $\begin{array}{c}10.07-15.59^{\#} \\
(\mathrm{n}=28)\end{array}$ & & $0.76-0.98^{\#}$ & 0.05 & 0.02 \\
\hline Marchei et al. [21] & 2005 & Italy & LC/MS & & $\begin{array}{c}1.06-33.02^{\#} \\
(\mathrm{n}=11)\end{array}$ & & & 0.24 & \\
\hline Ryu et al. [22] & 2006 & Korea & $\mathrm{LC} / \mathrm{MS} / \mathrm{MS}$ & & & & & 0.16 & \\
\hline Sorensen et al. [23] & 2007 & Denmark & GC/MS & $\begin{array}{c}1.19^{*} \\
(\mathrm{n}=301)\end{array}$ & $\begin{array}{l}21.06^{*} \\
(\mathrm{n}=27)\end{array}$ & $0.06^{*}$ & $0.33^{*}$ & 0.10 & 0.05 \\
\hline Okoli et al. [24] & 2007 & Columbia & HPLC/ECD & $\begin{array}{c}1.32^{*} \\
(\mathrm{n}=129)\end{array}$ & $\begin{array}{c}6.17^{*} \\
(\mathrm{n}=78)\end{array}$ & & & 0.05 & \\
\hline Man et al. [25] & 2009 & Malaysia & GC/MS & $\begin{array}{c}1.02^{*} \\
(\mathrm{n}=16)\end{array}$ & $\begin{array}{l}26.25^{*} \\
(\mathrm{n}=17)\end{array}$ & & & 0.04 & \\
\hline
\end{tabular}

Notes: ND, no detection; HPLC/UV, high performance liquid chromatography with ultra violet; GC/MS, gas chromatography with mass spectrophotometry; RIA, radioimmunoassay; HPLC/ECD, high performance liquid chromatography with electro chemical detection; LC/MS, high performance liquid chromatography with mass spectrophotometry; LC/MS/MS, high performance liquid chromatography with tandem mass spectrophotometry. ${ }^{*}:$ Mean, ${ }^{* *}$ : Median; ${ }^{*}$ : Range.

Table 3. Cost comparison by analytical method.

\begin{tabular}{lll}
\hline Analytical method & Initial cost & Running cost \\
\hline HPLC/UV & Low & Low \\
HPLC/ECD & Moderate & Low \\
LC/MS & High & Moderate \\
GC/MS & High & High \\
RIA & High & Moderate \\
LC/MS/MS & Extremely high & Moderate \\
GC/MS/MS & Extremely high & High \\
\hline
\end{tabular}

Notes: HPLC/UV, high-performance liquid chromatography with ultraviolet HPLC/ECD, high performance liquid chromatography with electrochemical detection; LC/MS, high performance liquid chromatography with mass spectrophotometry; GC/MS, gas chromatography with mass spectrophotometry; RIA, radioimmunoassay; LC/MS/MS, high performance liquid chromatography with tandem mass spectrophotometry; GC/MS/MS, high performance gas chromatography with tandem mass spectrophotometry. Cost categories: US\$1 = 100 yen; Initial costs: Low $=$ under US\$50,000, Moderate $=$ US $\$ 50,000 \sim$ US $\$ 100,000$, High $=$ US $\$ 100,000 \sim$ US $\$ 200,000$, Extremely high $=$ over US\$200,000; Running costs: Low = under US\$3000/year, Moderate $=$ US $\$ 3000 \sim$ US $\$ 5000 /$ year, High $=$ over US\$5000/year.

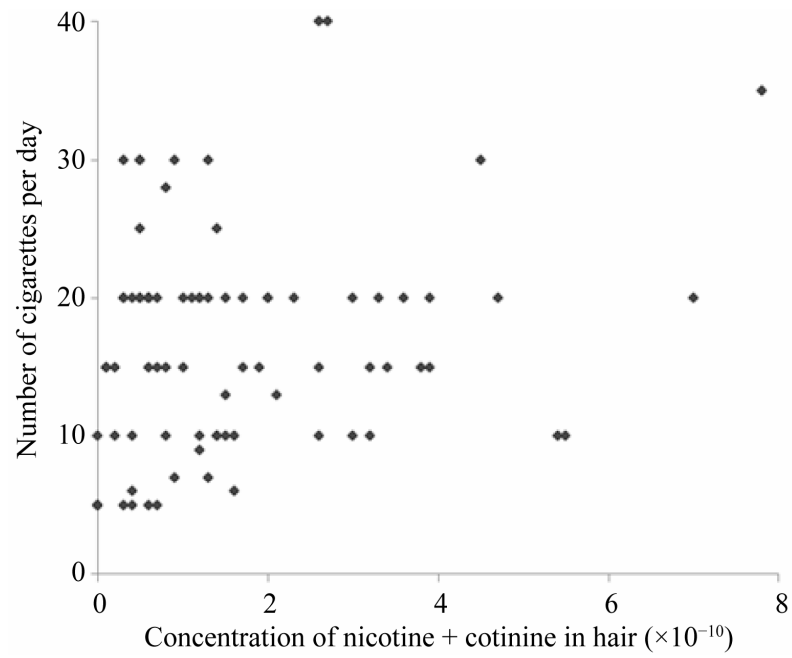

Figure 3. Correlation between concentrations of nicotine + cotinine in hair and number of cigarettes smoked per day; $r=$ $0.228, \mathrm{p}=0.040$. 
metabolic differences from nicotine to cotinine among individuals, we analyzed the total amounts of nicotine and cotinine. The total of nicotine and cotinine in hair may use as a predictive bio-marker of the number of cigarettes smoked per day.

In this study, mean concentrations of nicotine in hair samples were $1.60 \mathrm{ng} / \mathrm{mg}$ for non-smokers and 23.30 $\mathrm{ng} / \mathrm{mg}$ for smokers. Concentrations of cotinine in hair samples were $0.20 \mathrm{ng} / \mathrm{mg}$ for non-smokers and 1.70 $\mathrm{ng} / \mathrm{mg}$ for smokers. The detection limit was $0.10 \mathrm{ng} / \mathrm{mg}$ nicotine and $0.08 \mathrm{ng} / \mathrm{mg}$ cotinine in hair samples. When compared with previous studies, our method was within the same range of accuracy as other measurement methods for nicotine and cotinine in hair. Therefore, the HPLC/UV with column-switching method appears to have similar sensitivity as the GC/MS and HPLC/ECD methods. The MS method is known to be highly sensitive in identifying materials by mass, but the HPLC/UV method has been shown to be just as sensitive. We believe that the columns and detection devices in the HPLC/UV method have been thoroughly tested [26-28], and by introducing the simple improvement of the column-switching method to the HPLC/UV method, it is possible to markedly increase sensitivity.

This study found that both the initial and running costs of the present method are "Low", suggesting that experiments can be performed with this method for less than US\$53,000 per year. The GC/MS method, a major analytical method used for nicotine and cotinine measurement, was shown to cost over US\$105,000 per year. Measurement with HPLC/UV method is therefore able to reduce cost by half when compared with the GC/MS method. In addition, because HPLC and UV detectors are already used widely $[10,11]$, it is possible to reduce the initial costs. It is also possible to introduce a columnselection unit at the low cost of about US\$3000, reducing the total cost of this study to around US\$27,500. The present HPLC/UV with column-switching method had a sensitivity similar to that of the GC/MS method, as well as a low cost. Based on its accuracy and cost, we believe that measurement of nicotine and cotinine in hair samples using this HPLC/UV method would be useful in initial screening, such as in health check-ups. The HPLC/ UV with column-switching method is able to perform such screening at low cost and with the same accuracy as other analytical methods, thereby facilitating the study of the effects of smoking exposure.

This study had several limitations. Because smokers of self-reported their cigarette intake, results may have been underestimated. However, because the questionnaire used in this study was answered during home visiting interviews, we assume the subjects answered honestly. In the future, a comparison between the HPLC/UV with columnswitching method and other analytical methods will be necessary using the same samples.

\section{CONCLUSION}

In this study, we established a simple HPLC/UV with column-switching method for the determination of nicotine and cotinine in hair samples. Using this method, the nicotine and cotinine in hair were found to accurately reflect exposure to smoking. The HPLC/UV with column-switching method is able to detect nicotine and cotinine in hair with an equivalent sensitivity as GC/MS or HPLC/ECD, but at about the half cost of the GC/MS method. Therefore, the HPLC/UV with column-switching method could be more widely applied, particularly for use in screening surveys, in order to better understand the effects of smoking exposure.

\section{ACKNOWLEDGEMENTS}

The present study was supported by a Research Grant for Cardiovascular Disease from the Ministry of Health, Labor and Welfare. The present study was approved by the Fukushima Medical University Ethics Committee (approval number: 1166).

\section{REFERENCES}

[1] The Examination Organization about Smoking and Health Problems (2002) Smoking and health. Hokendohjinsha Inc., Tokyo.

[2] Whincup, P.H., Gilg, J.A., Emberson, J.R., Jarvis, M.J., Feyerabend, C., Bryant, A., Walker, M. and Cook, D.G. (2004) Passive smoking and risk of coronary heart disease and stroke: Prospective study with cotinine measurement. British Medical Journal, 329, 200-205. doi:10.1136/bmj.38146.427188.55

[3] Higashi, E., Sashikuma, F., Itani, S. and Muranaka, H. (1986) Simultaneous determination of nicotine and cotinine in urine by gas liquid chromatography. Eisei Kagaku, 32, 276-280. doi:10.1248/jhs 1956.32.276

[4] Yamamoto, M., Shibata, Y., Mugikura, M., Igarashi, T. and Satoh, K. (2000) Usefulness of urinary cotinine measurement in determining individual smoking status. Journal of Transportation Medicine, 54, 142-146.

[5] Heinrich, J., Holscher, B., Seiwert, M., Carty, C.L., Merkel, G. and Schulz, C. (2005) Nicotine and cotinine in adults' urine: The german environmental survey 1998. Journal of Exposure Analysis and Environmental Epidemiology, 15, 74-80. doi:10.1038/sj.jea.7500373

[6] Al-Delaimy, W.K. (2002) Hair as a biomarker for exposure to tobacco smoke. Tobacco Control, 11, 176-182. doi:10.1136/tc.11.3.176

[7] Klein, J., Blanchette, P. and Koren, G. (2004) Assessing nicotine metabolism in pregnancy: A novel approach using hair analysis. Forensic Science International, 145, 191-194. doi:10.1016/j.forsciint.2004.04.035

[8] Sporkert, F. and Pragst, F. (2000) Use of headspace solidphase microextraction (HP-SPME) in hair analysis for 
organic compounds. Forensic Science International, 107, 129-148. doi:10.1016/S0379-0738(99)00158-9

[9] Kim, S.R., Wipfil, H., Avila-Tang, E., Samet, J.M. and Breysse, P.N. (2009) Method validation for measurement of hair nicotine level in nonsmokers. Biomedical Chromatography, 23, 273-279. doi:10.1002/bmc.1110

[10] Ono, T., Tanida, K., Shibata, H., Konishi, H. and Shimakawa, H. (1986) High-performance liquid chromatographic determination of $6 \beta$-hydroxycortisol in urine. Chemical and Pharmaceutical Bulletin, 34, 2522-2527. doi:10.1248/cpb.34.2522

[11] Zdarova, K.J., Novotny, L., Antos, K., Zivna, H. and Kuca, K. (2010) Time-dependent changes in concentration of two clinically used acetylcholinesterase reactivators (HI-6 and obidoxime) in rat plasma determined by HPLC techniques after in vivo administration. Analytical Sciences, 26, 63-67. doi:10.2116/analsci.26.63

[12] Nakamura, H. (2003) The handbook to preprocess an analysis samples. Maruzen, Tokyo.

[13] Mizuno, A., Uematsu, T., Oshima, A., Nakamura, M. and Nakashima, M. (1993) Analysis of nicotine content of hair for assessing individual cigarette-smoking behavior. Therapeutic Drug Monitoring, 15, 99-104. doi:10.1097/00007691-199304000-00005

[14] Benowitz, N.L. (1994) Cotinine as a biomarker of environmental tobacco smoke exposure. Epidemiologic Reviews, 18, 188-204. doi:10.1093/oxfordjournals.epirev.a017925

[15] Zahlsen, K. and Nilsen, O.G. (1994) Nicotine in hair of smokers and non-smokers: Sampling procedure and gas chromatographic/mass spectrometric analysis. Pharmacology and Toxicology, 75, 143-149. doi:10.1111/j.1600-0773.1994.tb00337.x

[16] Eliopoulos, C., Klein, J., Phan, M.K., Knie, B., Greenwald, M., Chitayat, D. and Koren, G. (1994) Hair concentrations of nicotine and cotinine in woman and their newborn infants. Journal of the American Medical Association, 271, 621-623. doi:10.1001/jama.1994.03510320061031

[17] Eliopoulos, C., Klein, J. and Koren, G. (1996) Validation of self-reported smoking by analysis of hair for nicotine and cotinine. Therapeutic Drug Monitoring, 18, 532-536. doi:10.1097/00007691-199610000-00002

[18] Nafstad, P., Jaakkola, J.J.K., Hagen, J.A., Zahlsen, K. and Magnus, P. (1997) Hair nicotine concentrations in mothers and children in relation to parental smoking. Journal of Exposure Analysis and Environmental Epidemiology, 7, 235-239.

[19] Al-Delaimy, W.K., Crane, J. and Woodward, A. (2002) Is the hair nicotine level a more accurate biomarker of en- vironmental tobacco smoke exposure than urine cotinine? Journal of Epidemiology and Community Health, 56, 6671. doi:10.1136/jech.56.1.66

[20] Chetiyanukornkul, T., Toriba, A., Kizu, R., Kimura, K. and Hayakawa, K. (1996) Hair analysis of nicotine and cotinine for evaluating tobacco smoke exposure by liquid chromatography-mass spectrometry. Biomedical Chromatography, 18, 655-661. doi:10.1002/bmc.369

[21] Marchei, E., Durgbanshi, A., Rossi, S., Garcia-Algar, O., Zuccaro, P. and Pichini, S. (2005) Determination of arecoline (areca nut alkaloid) and nicotine in hair by highperformance liquid chromatography/electrospray quadrupole mass spectrometry. Rapid Communications in Mass Spectrometry, 19, 3416-3418. doi:10.1002/rcm.2183

[22] Ryu, H.J., Seong, M.W., Nam, M.H., Kong, S.Y. and Lee, D.H. (2006) Simultaneous and sensitive measurement of nicotine and cotinine in small amounts of human hair using liquid chromatography/tandem mass spectrometry. $R a-$ pid Communications in Mass Spectrometry, 20, 27812782. doi:10.1002/rcm.2659

[23] Sorensen, M., Bisgaard, H., Stage, M. and Loft, S. (2007) Biomarkers of exposure to environmental tobacco smoke in infants. Biomarkers, 12, 38-46. doi: $10.1080 / 13547500600943148$

[24] Okoli, C.T., Hall, L.A., Rayens, M.K. and Hahn, E.J. (2007) Measuring tobacco smoke exposure among smoking and nonsmoking bar and restaurant workers. Biological Research for Nursing, 9, 81-89. doi:10.1177/1099800407300852

[25] Man, C.N., Ismail, S., Harn, G.L., Lajis, R. and Awang, R. (2009) Determination of hair nicotine by gas chromatography-mass spectrometry. Journal of Chromatography B, 877, 339-342. doi:10.1016/i.jchromb.2008.12.014

[26] Pichini, S., Altieri, I., Pellegrini, M., Pacifici, R. and Zuccaro, P. (1997) Hair analysis for nicotine and cotinine: Evaluation of extraction procedures, hair treatments, and development of reference material. Forensic Science International, 84, 243-252. doi:10.1016/S0379-0738(96)02068-3

[27] Pacifici, R., Pichini, S., Altieri, I., Rosa, M., Bacosi, A., Caronna, A. and Zuccaro, P. (1993) Determination of nicotine and two major metabolites in serum by solid-phase extraction and high-performance liquid chromatography, and high-performance liquid chromatography-particle beam mass spectrometry. Journal of Chromatography B, 612, 209-213. doi:10.1016/0378-4347(93)80165-Z

[28] Pichini, S., Altieri, I., Pellegrini, M., Pacifici, R. and Zuccaro, P. (1997) The analysis of nicotine in infants' hair for measuring exposure to environmental tobacco smoke. $F_{O}$ rensic Science International, 84, 253-258. doi:10.1016/S0379-0738(96)02069-5 